\title{
The role of families in population health: the case of reproductive health of women and adolescents in Mozambique
}

\author{
Leonardo Chavane
}

Department of Community Health, Faculty of Medicine, University Eduardo Mondlane, Maputo, Mozambique

\begin{abstract}
The family is a key social context within which health is maintained, illness occurs and health-related decisions are made. The family is also a mirror of what happens at the macro-level of society. In the African context, the family concept goes beyond the small nuclear family composed of close relatives and includes extended family members sometimes with a very distant relationship. Tradition influences the organization, the functioning, the decision-making process regarding reproductive health and healthcare-seeking behaviours, ultimately influencing access and usage of healthcare.

Based on a desk review and the author's personal experience this paper explores family practices and their relation to women's and adolescent's reproductive health in Mozambique. It finds that this has been characterized by a high level of morbidity and mortality and at the same time very high fertility and low utilization of health care services and technologies including family planning.

Traditional beliefs, cultural norms, gender imbalance, and myths related to reproductive health have a considerable impact on health-seeking behaviours and ultimately in the access and utilization of health services in Mozambique. Despite the role women play in fostering family health, some practices hinder their possibility to enjoy healthier reproductive life.

In Mozambique, there is a mismatch between the health promotion, prevention and care interventions at the health facilities, and between the messages and practices at the community and family levels. There is a need for a better understanding of the cultural aspect of the community and family level in order to ensure changes in practices and bring about positive change to the the women's and adolescent's reproductive health status.
\end{abstract}

KEY WORDS: family health, maternal, reproductive, health, Mozambique.

ADDRESS FOR CORRESPONDENCE: Leonardo Chavane, PhD, Department of Community Health, Faculty of Medicine, University Eduardo Mondlane, Av. Salvador Allend, Maputo, Mozambique, e-mail: leochavane@gmail.com

\section{INTRODUCTION}

The family is a key social context within which health is maintained, illness occurs and health-related decisions are made [1]. In many countries the bulk of social and cultural practices, as well as heath behaviours, are intimately connected with the notion of family. This has been recognised by the World Health Organization (WHO), which emphasises that it is within families that individuals are born, nurtured, learn to socialize, and it is where an individual's behaviours and views take shape [2].

\section{CHANGES IN THE CONTEMPORARY AFRICAN SOCIETY}

In the African context, often the family is viewed as a wider concept than that of a nuclear family, and encompasses children, parents, grandparents, uncles, aunts, brothers and sisters who may have their own children and other immediate relatives [3]. Traditionally the members of such extended family could live together in a traditional compound consisting of several houses close to one another or separated by some distance. In case of geo- 
graphic separation, they would gather together to make important decisions concerning the family. Usually the members of the wider family would belong exclusively either to a paternal or maternal descent [4]. The African society has been undergoing a process of profound changes affecting all aspects of its traditional life [5]. Various factors contribute to these changes: the westernization of the African society with its stress on individual success, competitiveness and financial gain, modern education that often promotes personal values at the expense of communal values, modernization of the society with an increased pace of life demanding more time to be dedicated to work, the process of globalization that increases the gap between the rich and the poor, and the process of urbanization that encourages many people to move to cities in search of work and better living conditions. Despite these changes, the impact of traditional belief systems, including health-related taboos and myths surrounding maternal and reproductive health, continues to be high especially within rural communities.

In this paper we aim to explore the influence of family-related practices and attitudes on maternal, reproductive and adolescent health in the Mozambican context.

\section{THE ROLE OF FAMILY AND OF ITS INDIVIDUAL MEMBERS}

Family health bridges the gap between individual health on one hand and community health/public health on the other. The family can act as a health-support system facilitating positive health outcomes [6]. It has been shown, for instance, that the presence of both biological parents in the family reduces the likelihood of occurrence of mental disorders in children and adolescents [2]. In addition, different components of the family system mutually interact with each other. Family-based attitudes to health influence the health of its individual members, while simultaneously the health of individual members impacts how the family functions as a social system and unit of health care [1].

Historically and traditionally, women play a key role in building family health. Their impact is affected by social status, education, employment and cultural practices that permit or inhibit them from family decision-making. Women's roles are therefore both determinant in family health status, while also shaped by the functioning of the family. In many contexts, women have been socialized to provide care and maintenance to the family unit by procuring and preparing food, giving care to dependent family members, and by socializing children to become productive adults. Thus, women's roles within families in developing countries have frequently positioned them as health managers or promoters of overall family health, particularly for children [7].

\section{THE CASE OF MOZAMBIQUE}

Mozambique is a sub-Saharan country with a population of around 30 million. After independence from Portugal in 1975 and a subsequent civil war which last- ed until 1992, Mozambique has shown robust economic growth and declining poverty rates over the last 20 years. Nonetheless, $46 \%$ of the population still lives below poverty line, with an unequal distribution across the country. The uneven availability of basic services, especially health and education, are amongst the key factors underlying this economic disparity [8].

The last population census conducted in 2017 revealed a high total fertility rate of 5.2 per woman at reproductive age. The population growth rate is estimated at $2.8 \%$, which generates a young population structure where $45 \%$ of the total population is under 15 years old. Infant mortality is 147 per 1,000 live births. The life expectancy at birth is estimated at 49 years [9]. The burden of disease is very high and dominated by preventable and curable diseases, most notably HIV/AIDS, malaria and respiratory diseases.

Data from a national survey on family budgets conducted in 2015 indicate that there were around 5 million households in Mozambique, out of which 1.5 million were located in urban areas and 3.5 million living in rural areas. This distribution pattern results in a high proportion of rural families. Overall, the majority of households consisted of 3-4 or 5-6 members. The average number of people per household was 5.0. Monthly expenses on health per family amount to $20 \%$ of total expenses in urban areas, but just $0.5 \%$ in rural area. The rural population suffers from lack of availability of services and lack of resources to access services at household level. Most of the family savings are spent on food and housing [10].

Maternal mortality in Mozambique remains high. The greatest contribution to maternal mortality comes from the poor and vulnerable communities, which frequently reside in remote and rural areas with limited access to health care services. The 2015 United Nation interagency group estimation of maternal mortality showed a ratio of 489 maternal deaths per 100 thousand live births. Although this level of mortality represents an important reduction from the level of 1990, which was estimated at 1,390 maternal deaths [11], it continues to be unacceptably high. Data from the 2011 Demographic and Health Survey (DHS) indicate that around $14 \%$ of women aged 20-24 years were first married or in partnership before the age of 15 , and $48 \%$ of women aged 20-24 years were first married or in partnership before the age of 18 [12].

The access and utilization of facility-based health services for maternal, reproductive and adolescent health are weak and are affected by a number of limiting factors and taboos. The nationwide survey on HIV, Aids and Malaria indicators (IMASIDA) conducted in 2017 revealed that only $55 \%$ of pregnant women accessed and attended at least 2 antenatal consultations, and only $15 \%$ of adolescents aged 15-19 declared to be using any modern contraception method [13]. In rural areas antenatal 
care is sought at the heath facility for the purpose of opening the antenatal record. Women without antenatal cards feared mistreatment during labour [14].

The decision-making process to seek care at health facilities is challenging and can be delayed and particularly complex if an emergency occurs. There are important factors that prevent timely care-seeking for obstetric emergencies and delivery. Unfamiliarity with warning signs, especially among partners, the practice of discouragement from revealing pregnancy early in gestation, complex and untimely decision-making processes, are the most commonly cited barriers [14].

\section{THE ROLE OF SOCIETY AND CULTURE}

The gender relationship plays an important role at family and community level in shaping health in Mozambique mainly through two mechanisms: (a) gender inequality in decision making and responsibility for pregnancy and (b) community beliefs that attendance at some sexual and reproductive health (SRH) services at a health facility, particularly if supported by a male partner, is indicative of a woman's HIV-positive status, which can ultimately lead to stigmatization in the community. In fact, research in Mozambique has shown that these factors have also resulted in the stigmatization of partner support in accessing maternal and reproductive health services. In effect, in some regions of the country it is socially unacceptable for men to provide visible support to their partners in such instances. Providing support to a pregnant partner, including accompanying her to an antenatal care appointment, meant that men had to face disapproval of close friends and family members. Providing physical or emotional support to a pregnant partner implied male weakness. This taboo is fundamentally linked to unequal gender roles and the importance of the man appearing superior to his partner [15].

Given these and other cultural specificities, is increasingly being recognized that the existing interventions in the area of SRH in Sub-Saharan Africa are not having the desired effects. New approaches, which take into account the local lifestyles, attitudes, beliefs and traditional practices forming the basis of community perceptions of health and illness, life and death, and sexuality, have come to be recognized as a potentially more effective way to intervene in matters related to SRH. At the community level, recognizing this socio-cultural aspect means being aware of the norms, beliefs and practices of the community and the role that religious and traditional leaders, traditional health practitioners, family members, schools and health units all play in transferring and disseminating knowledge.

\section{THE ROLE OF COMMUNICATION}

Effective communication can play a vital role for the family to realise its function as a driver of good health. Within the family communication serves as the medium through which shared beliefs, feelings, and emotions are transmitted and family functioning is maintained [16].

Some recurring issues related to maternal and reproductive health in Mozambique can be traced to poor communication and the resulting lack of knowledge on the aetiology of HIV/AIDS, prevention of sexually transmitted diseases, and family planning. It is common for males to resist family planning, which is underpinned by the prohibition of condom use in some religions, the belief that more children represent increased potential for wealth and income for the family, and early traditional marriage, viewed in some communities as a source of wealth for the girl's family. Unfortunately, early marriage is often associated with complications in adolescent health.

The inconsistency of the messages being transmitted in the Mozambican context mean that there is often a weak relationship between the main actors responsible for the dissemination of SRH, in particular the formal health system, the school and the community. At the community level, the teachings focus on initiation rites, religion, taboos and traditional medicine. Meanwhile, in schools and health units the approach encourages preventative measures such as family planning, condom use, gender equality and sexual and reproductive rights. One example of the conflicting messages between traditional and formal education is the fact that in the community girls are considered ready to get married and have children after the first menstruation, while schools and health facilities advocate delaying sexual activity. Studies reveal that a variety of factors interfere with effective communication of messages related to sexuality between parents and adolescents as result of gender differences, level of education, religion, traditional norms which establish who can and cannot provide such information to young women, and the fear of the parents to make young women curious and push them to premarital sex [17]. For SRH interventions to succeed at community level they need to align to both modern and traditional practices. One of the Mozambican community leaders once captured the root cause behind barriers for good health in the following way: "Sometimes we look at things without understanding the risks they bring... we think of things as normal because they happen often, for example now the problem of HIV and AIDS kills many people, but as we are all so used to hearing about it, the disease has become something normal to us. We need to go back to thinking that HIV and AIDS is not normal or inevitable and we need to know how to protect ourselves from it" [16]. For the maternal and reproductive health interventions to succeed at community level, key stakeholders in these communities need to be actively engaged from the outset, acting as advocates for change at the grass-roots level, and using their cultural foundation to form more appropriate plans. In this way, knowledge-sharing partnerships can be developed and common objectives and approaches established [18]. 
A new strategy aiming to engage families in promotion and adoption of healthy lifestyles at community level is currently being promoted in Mozambique, mainly in rural areas. The strategy called Model Family was first introduced in 2015 within the Ministry of Health's Strategy of Health Promotion [19]. According to the strategy, a family is given 'model family' status if it adopts a set of hygiene and sanitation practices (availability and proper use of latrines, use of tippy tap, employment of household water treatment and water storage, a corner set aside for washing and drying utensils) together with other health aspects such as use of mosquito nets and whether the family has children under five years of age. The status of a child's health card is checked periodically, and a pregnant woman's health card will be checked to assess whether she has had regular prenatal checks [20]. The model family strategy is still new in Mozambique and therefore results of its impact are yet to be documented.

\section{CONCLUSIONS}

In the context of present-day Mozambique, the family appears to be a crucial setting within which to act on the determinants of women's and adolescent's health. This is especially the case of determinants related to cultural and social believes, norms, myths and taboos. At the same time, it is important to understand and appreciate that families are different in their structure and functioning, and this has an impact in the health-related decision making process.

\section{DISCLOSURE}

The author declares no conflict of interest.

\section{References}

1. Bowles J, Kington RS. The impact of family function on health of African American elderly. J Comp Fam Stud 2019; 29 (2): 337 347.

2. World Health Organization. Family as Centre of Health Development. Report of the Regional Meeting Bangkok, Thailand, 18-20 March 2013. Available from: http://apps.searo.who.int/ PDS_DOCS/B4972.pdf (accessed: 7 August 2019).

3. Families and inclusive societies in Africa. Available from: http://ecommons.hsrc.ac.za/handle/20.500.11910/12372 (accessed: 8 August 2019).

4. Concept of family in Africa. Available from: http://mojaafryka. weebly.com/concept-of-family.html (accessed: 7 August 2019).

5. Haregu TN, Beguy D, Ezeh A. Changing Family Structure and Fertility in Sub-Saharan Africa, African Population and Health Research Center, 2015.

6. Manciaux M, Belsey MA. Family Health. Global Perspectives in Health. Encyclopedia of Life Support Systems (EOLSS), vol. I. UNESCO, Oxford 2009. Available from: https://www.eolss.net/ ebooklib/ebookcontents/E1-14-ThemeContents.pdf (accessed: 8 August 2019).

7. Goodwin PY, Garrett DA, Galal O. Women and family health: the role of mothers in promoting family and child health. Int J Glob Heal Heal Disparities 2005; 4 (1): 30-42.
8. Unated Nations Population Fund. Mundos distantes: saúde reprodutiva e direitos numa era de desigualdades. UNFPA Mozambique. Available from: https://www.ungm.org/UNUser/Documents/DownloadPublicDocument?docId=693000 (accessed: 8 August 2019).

9. Instituto Nacional de Estatística (INE). IV Recenseamento Geral da População e Habitação 2017. IV Recenseamento Geral da População e Habitação 2017. Resultados Definitivos Moçambique Maputo - Abril, 2019. Instituto Nacional de Estatistica, Maputo. Available from: http://www.ine.gov.mz/iv-rgph-2017/ mocambique/censo-2017-brochura-dos-resultados-definitivos-do-iv-rgph-nacional.pdf/view (accessed: 23 August 2019).

10. Instituto Nacional de Estatística. Relatório final do inquérito ao orçamento familiar - iof-2014/15. Instituto Nacional de Estatística, Maputo 2015. Available from: http://www.ine.gov. $\mathrm{mz} /$ operacoes-estatisticas/inqueritos/inquerito-sobre-orcamento-familiar/relatorio-final-do-inquerito-ao-orcamento-familiar-iof-2014-15/view (accessed: 8 August 2019).

11. World Health Organization. Maternal mortality: 1990 to 2015. Estimates by WHO, UNICEF, UNFPA, World Bank Group. Available from: http://www.who.int/reproductivehealth/publications/monitoring/maternal-mortality-2015/en/ (accessed: 15 September 2019).

12. National Institute of Statistics \& Ministry of Health. Moçambique, Inquerito Demográfico e de Saúde 2011. National Institute of Statistics, Maputo 2013.

13. Inquérito de Indicadores de Imunização, Malária e HIV/SIDA em Moçambique (IMASIDA) 2015 - Relatório de Indicadores Básicos. Instituto Nacional de Estatistica, Maputo. Available from: //mz.usembassy.gov/wp-content/uploads/sites/182/2017/06/ IMASIDA-2016_Relatorio-de-Indicadores-Basicos-for-Web.pdf (accessed: 24 September 2019).

14. Munguambe K, Boene H, Vidler M, et al. Barriers and facilitators to health care seeking behaviours in pregnancy in rural communities of southern Mozambique. Reprod Health. Reproductive Health 2016; 13 (Suppl 1): 31-45.

15. Audet CM, Chire YM, Vaz LM, et al. Barriers to male involvement in antenatal care in rural Mozambique. Qual Health Res 2016; 26 (12): 1721-1731.

16. Rodriguez V, Corona R, Bodurtha JN, Quillin J.M. Family ties: the role of family context in family health history communication about cancer. J Heal Commun 2016; 21 (3): 346-355.

17. Frederico M, Arnaldo C, Michielsen K, Decat P. Adult and young women communication on sexuality: a pilot intervention in Maputo-Mozambique. Reprod Health 2019; 16 (1): 144-155.

18. Understanding the Role of Culture in Sexual and Reproductive Health in Mozambique. Available from: http://mdgfund.org/ country/mozambique/story/UnderstandingtheRoleofCultureinSexualandReproductiveHealthinMozambique (accessed: 8 August 2019).

19. Ministry of Health Mozambique. Estratégia Nacional de Promoção de Saúde 2015-2019. Ministry of Health Mozambique, Maputo 2015.

20. UNICEF. Case Study 4D. Mozambique - Promoting healthy lifestyles through 'model families'. UNICEF, Maputo 2016. Available from: //whatworks.co.ke/downloads/CS\%204D\%20Mozambique\% 20Model\%20Family\%20Concept-final.pdf (accessed: 8 August 2019). 